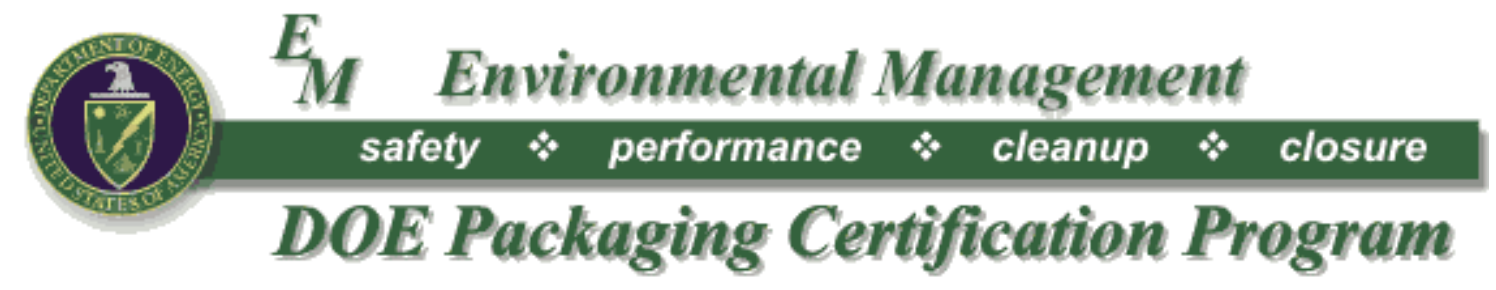

\title{
Definition of "Small Gram Quantity Contents” for Type B Radioactive Material Transportation Packages: Activity-Based Content Limitations
}

This work was sponsored by the Department of Energy

Office of Packaging and Transportation (EM-45)

and performed by members of the

Packaging and Transportation Safety Group:

S. Sitaraman, S. Kim, D. Biswas, R. Hafner, and B. Anderson

Global Security Principal Directorate

Lawrence Livermore National Laboratory

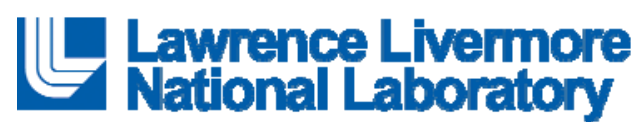

October 29, 2010 
This document was prepared as an account of work sponsored by an agency of the United States government. Neither the United States government nor Lawrence Livermore National Security, LLC, nor any of their employees makes any warranty, expressed or implied, or assumes any legal liability or responsibility for the accuracy, completeness, or usefulness of any information, apparatus, product, or process disclosed, or represents that its use would not infringe privately owned rights. Reference herein to any specific commercial product, process, or service by trade name, trademark, manufacturer, or otherwise does not necessarily constitute or imply its endorsement, recommendation, or favoring by the United States government or Lawrence Livermore National Security, LLC. The views and opinions of authors expressed herein do not necessarily state or reflect those of the United States government or Lawrence Livermore National Security, LLC, and shall not be used for advertising or product endorsement purposes.

This work performed under the auspices of the U.S. Department of Energy by Lawrence Livermore National Laboratory under Contract DE-AC52-07NA27344. 


\title{
Definition of “Small Gram Quantity Contents” for Type B Radioactive Material Transportation Packages: Activity-Based Content Limitations
}

\begin{abstract}
Background and Introduction
Since the 1960's, the Department of Transportation Specification (DOT Spec) 6M packages have been used extensively for transportation of Type B quantities of radioactive materials between Department of Energy (DOE) facilities, laboratories, and productions sites. However, due to the advancement of packaging technology, the aging of the $6 \mathrm{M}$ packages, and variability in the quality of the packages, the DOT implemented a phased elimination of the $6 \mathrm{M}$ specification packages (and other DOT Spec packages) in favor of packages certified to meet federal performance requirements. ${ }^{[1]}$ DOT issued the final rule in the Federal Register on October 1, 2004 requiring that use of the DOT Specification 6M be discontinued as of October 1, 2008. A main driver for the change was the fact that the $6 \mathrm{M}$ specification packagings were not supported by a Safety Analysis Report for Packaging (SARP) that was compliant with Title 10 of the Code of Federal Regulations part 71 (10 CFR 71). ${ }^{[2,3]}$
\end{abstract}

Therefore, materials that would have historically been shipped in $6 \mathrm{M}$ packages are being identified as contents in Type B (and sometimes Type A fissile) package applications and addenda that are to be certified under the requirements of 10 CFR 71. The requirements in 10 CFR 71 include that the Safety Analysis Report for Packaging (SARP) must identify the maximum radioactivity of radioactive constituents and maximum quantities of fissile constituents (10 CFR 71.33(b)(1) and 10 CFR 71.33(b)(2)), and that the application (i.e., SARP submittal or SARP addendum) demonstrates that the external dose rate (due to the maximum radioactivity of radioactive constituents and maximum quantities of fissile constituents) on the surface of the packaging (i.e., package and contents) not exceed $200 \mathrm{mrem} / \mathrm{hr}$ (10 CFR 71.35(a), 10 CFR 71.47(a)).

It has been proposed that a 'Small Gram Quantity" of radioactive material be defined, such that, when loaded in a transportation package, the dose rates at external points of an unshielded packaging not exceed the regulatory limits prescribed by 10 CFR 71 for non-exclusive shipments. The mass of each radioisotope presented in this paper is limited by the radiation dose rate on the external surface of the package, which per the regulatory limit should not exceed $200 \mathrm{mrem} / \mathrm{hr}$. The results presented are a compendium of allowable masses of a variety of different isotopes (with varying impurity levels of beryllium in some of the actinide isotopes) that, when loaded in an unshielded packaging, do not result in an external dose rate on the surface of the package that exceeds $190 \mathrm{mrem} / \mathrm{hr}$ (190 mrem $/ \mathrm{hr}$ was chosen to provide $5 \%$ conservatism relative to the regulatory limit). These mass limits define the term "Small Gram Quantity" (SGQ) contents in the context of radioactive material transportation packages. The term SGQ is isotope-specific and pertains to contents in radioactive material transportation packages that do not require shielding and still satisfy the external dose rate requirements. Since these calculated mass limits are for contents without shielding, they are conservative for packaging materials that provide some limited shielding or if the contents are placed into a shielded package. 
The isotopes presented in this paper were chosen as the isotopes that Department of Energy (DOE) sites most likely need to ship. Other more rarely shipped isotopes, along with industrial and medical isotopes, are planned to be included in subsequent extensions of this work.

\section{Isotopes Considered}

Table 1 provides a list of the isotopes considered in this report. This list of isotopes was developed with input from many groups in the DOE complex and is intended to represent a comprehensive list of the isotopes that would generally need to be shipped for purposes related to DOE activities.

Table 1. Isotopes Considered

\begin{tabular}{|c|c|c|c|c|}
\hline Am-241 & Pu-242 & Pu-241 w/Be & Hf-181 & Ru-106 \\
\hline Am-243 & Cf-252 & Pu-242 w/Be & Ho-166 & Sc-46 \\
\hline Cm-244 & Am-241 w/Be & Ac-227 & Ir-192 & Se-75 \\
\hline Cm-248 & Am-243 w/Be & Cd-109 & Mn-54 & Sm-145 \\
\hline Np-237 & Cm-244 w/Be & Co-60 & Pb-210 & Sr-90 \\
\hline Pu-238 & Np-237 w/Be & Cs-137 & Pd-103 & Tm-170 \\
\hline Pu-239 & Pu-238 w/Be & Eu-152 & Pm-147 & Yb-169 \\
\hline Pu-240 & Pu-239 w/Be & Fe-59 & Po-210 & Zn-65 \\
\hline Pu-241 & Pu-240 w/Be & Gd-153 & Ra-226 & Zr-95 \\
\hline
\end{tabular}

\section{Approach}

For each of the isotopes considered in this analysis, the source term was determined. Table 2 presents the source terms for the neutron-emitting isotopes and the neutron-emitting actinides with various weight percentages of beryllium. Table 3 presents the source terms of the gammaemitting isotopes. All sources are based on $1 \mathrm{~g}$ of the radioisotope and represent peak values that are not necessarily at the beginning of life of an isotope.

The gamma and neutron source spectra from the neutron emitters were obtained using the computer code RASTA. ${ }^{[4]}$ The oxide chemical form was assumed for determining the source terms for the neutron-emitting isotopes (Table 2) because this is the form of these isotopes most commonly shipped, and also to account for the $(\alpha, n)$ reaction that occurs with the natural occurring oxygen-17 and oxygen-18 isotopes.

Light element impurities that could result in $(\alpha, n)$ reactions were conservatively assumed to be beryllium. For the isotopes with beryllium impurities, the neutron source from the $(\alpha, n)$ reaction was obtained for weight percentages of beryllium from $0-90 \%$. The source terms for the pure gamma emitters were obtained using the computer code ORIGEN-ARP. ${ }^{[5]}$

Two different shielding models were used for the calculations: (1) the Voided Sphere Model, and (2) the Model 9977-96 radioactive material transportation packaging. The source terms, along with the shielding models, were used to calculate the dose rates with MCNP. ${ }^{[6]}$ The "Voided Sphere Model" is used to determine limiting isotopic masses with no shielding present and only an air gap between the point source and the point of dose rate determination. A representation of the Voided Sphere Model is given in Figure 1. The distance between the point source and the point of dose rate determination was chosen as $15.6 \mathrm{~cm}$. This distance of $15.6 \mathrm{~cm}$ corresponds to 
the distance from the inner wall of the containment vessel to the outer drum wall in the Model 9977-96 radioactive material transportation packaging. In this way, the limiting mass results from the Voided Sphere Model can be compared to the limiting masses resulting from the Model 9977-96 transportation packaging. A diagram of the Model 9977-96 Packaging is shown in Figure 2. A graphical representation of the shielding model used in the MCNP calculations for the 9977-96 Package is depicted in Figure 3. The DOE Certificates of Compliance for the Model 9977-96 provides further details concerning the packaging. ${ }^{[7,8]}$

Table 2. Source Terms for Neutron-Emitting Isotopes

\begin{tabular}{|c|c|c|c|c|c|c|c|c|c|c|c|}
\hline \multicolumn{12}{|c|}{ Actual Source [Particles per Second] for One Gram Source } \\
\hline \multirow{3}{*}{ Isotope } & \multirow{3}{*}{ Gamma } & \multicolumn{10}{|c|}{$\begin{array}{ll} & \text { Neutron } \\
\end{array}$} \\
\hline & & \multicolumn{10}{|c|}{ Weight Percent Beryllium } \\
\hline & & $\mathbf{0}$ & 0.1 & 0.5 & 1 & 5 & 10 & 30 & 50 & 70 & 90 \\
\hline Am-241 & 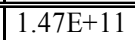 & $2.76 \mathrm{E}+03$ & $2.64 \mathrm{E}+04$ & $1.20 \mathrm{E}+05$ & $2.35 \mathrm{E}+05$ & $1.06 \mathrm{E}+06$ & $2.09 \mathrm{E}+06$ & $5.05 \mathrm{E}+06$ & $\overline{7.05 \mathrm{E}+06}$ & $8.49 \mathrm{E}+06$ & $9.58 \mathrm{E}+06$ \\
\hline Am-243 & $1.96 \mathrm{E}+10$ & $1.42 \mathrm{E}+02$ & $\mathrm{NC}$ & $\mathrm{NC}$ & $\mathrm{NC}$ & $\mathrm{NC}$ & $1.07 \mathrm{E}+05$ & $2.57 \mathrm{E}+05$ & $3.57 \mathrm{E}+05$ & $4.30 \mathrm{E}+05$ & $4.84 \mathrm{E}+05$ \\
\hline Cf-252 & $9.61 \mathrm{E}+12$ & $2.31 \mathrm{E}+12$ & NA & NA & NA & NA & NA & NA & NA & \begin{tabular}{|l|} 
NA \\
\end{tabular} & NA \\
\hline Cm-244 & $3.18 \mathrm{E}+11$ & $1.09 \mathrm{E}+07$ & $1.16 \mathrm{E}+07$ & $1.43 \mathrm{E}+07$ & $1.76 \mathrm{E}+07$ & $4.17 \mathrm{E}+07$ & $7.14 \mathrm{E}+07$ & $1.57 \mathrm{E}+08$ & $2.14 \mathrm{E}+08$ & $2.56 \mathrm{E}+08$ & $2.87 \mathrm{E}+08$ \\
\hline Cm-248 & \begin{tabular}{|l|}
$2.20 \mathrm{E}+08$ \\
\end{tabular} & \begin{tabular}{|l|}
$4.03 \mathrm{E}+07$ \\
\end{tabular} & NA & NA & NA & NA & NA & NA & \begin{tabular}{|l|} 
NA \\
\end{tabular} & NA & NA \\
\hline Np-237 & $7.09 \mathrm{E}+07$ & $3.52 \mathrm{E}-01$ & $\mathrm{NC}$ & $\mathrm{NC}$ & $\mathrm{NC}$ & $\mathrm{NC}$ & $2.61 \mathrm{E}+02$ & $6.31 \mathrm{E}+02$ & $8.80 \mathrm{E}+02$ & $1.06 \mathrm{E}+03$ & $1.20 \mathrm{E}+03$ \\
\hline Pu-238 & $7.15 \mathrm{E}+07$ & $1.65 \mathrm{E}+04$ & $1.35 \mathrm{E}+05$ & $6.01 \mathrm{E}+05$ & $1.17 \mathrm{E}+06$ & $5.06 \mathrm{E}+06$ & $1.04 \mathrm{E}+07$ & $2.52 \mathrm{E}+07$ & $3.53 \mathrm{E}+07$ & $4.25 \mathrm{E}+07$ & $4.80 \mathrm{E}+07$ \\
\hline Pu-239 & $9.80 \mathrm{E}+07$ & \begin{tabular}{|c|}
$3.96 \mathrm{E}+01$ \\
\end{tabular} & $3.83 \mathrm{E}+02$ & $1.74 \mathrm{E}+03$ & $3.40 \mathrm{E}+03$ & $1.54 \mathrm{E}+04$ & $3.03 \mathrm{E}+04$ & $7.31 \mathrm{E}+04$ & $1.02 \mathrm{E}+05$ & $1.23 \mathrm{E}+05$ & $1.38 \mathrm{E}+05$ \\
\hline Pu-240 & $9.04 \mathrm{E}+08$ & $1.17 \mathrm{E}+03$ & $2.44 \mathrm{E}+03$ & $7.46 \mathrm{E}+03$ & $1.36 \mathrm{E}+04$ & $5.80 \mathrm{E}+04$ & $1.13 \mathrm{E}+05$ & $2.71 \mathrm{E}+05$ & $3.77 \mathrm{E}+05$ & $4.54 \mathrm{E}+05$ & $5.11 \mathrm{E}+05$ \\
\hline Pu-241 & $1.31 \mathrm{E}+11$ & $2.46 \mathrm{E}+03$ & $\mathrm{NC}$ & $\mathrm{NC}$ & $\mathrm{NC}$ & $\mathrm{NC}$ & $1.86 \mathrm{E}+06$ & $4.50 \mathrm{E}+06$ & $6.28 \mathrm{E}+06$ & $7.56 \mathrm{E}+06$ & $8.53 \mathrm{E}+06$ \\
\hline Pu-242 & $1.31 \mathrm{E}+07$ & $1.72 \mathrm{E}+03$ & $1.74 \mathrm{E}+03$ & $1.81 \mathrm{E}+03$ & $1.90 \mathrm{E}+03$ & $2.54 \mathrm{E}+03$ & $3.33 \mathrm{E}+03$ & $5.58 \mathrm{E}+03$ & $7.09 \mathrm{E}+03$ & $8.16 \mathrm{E}+03$ & $8.97 \mathrm{E}+03$ \\
\hline
\end{tabular}

Table 3. Source Terms for Gamma-Emitting Isotopes

\begin{tabular}{|c|c|c|c|}
\hline \multicolumn{4}{|c|}{$\begin{array}{c}\text { Actual Source } \\
\text { (Photons per Second) for One Gram Source }\end{array}$} \\
\hline Isotope & $\begin{array}{c}\text { [Gammas per } \\
\text { Second] }\end{array}$ & Isotope & $\begin{array}{l}\text { [Gammas per } \\
\text { Second] }\end{array}$ \\
\hline Ac-227 & $8.41 \mathrm{E}+12$ & Pm-147 & $7.52 \mathrm{E}+11$ \\
\hline Cd-109 & $8.95 \mathrm{E}+13$ & Po-210 & $1.75 \mathrm{E}+09$ \\
\hline Co-60 & $8.56 \mathrm{E}+13$ & Ra-226 & $1.25 \mathrm{E}+11$ \\
\hline Cs-137 & $3.25 \mathrm{E}+12$ & Ru-106 & $1.93 \mathrm{E}+14$ \\
\hline Eu-152 & $1.48 \mathrm{E}+13$ & Sc-46 & $2.42 \mathrm{E}+15$ \\
\hline Fe-59 & $1.93 \mathrm{E}+15$ & Se-75 & $1.09 \mathrm{E}+15$ \\
\hline Gd-153 & $2.23 \mathrm{E}+14$ & Sm-145 & $1.31 \mathrm{E}+14$ \\
\hline Hf-181 & $1.15 \mathrm{E}+15$ & Sr-90 & $1.78 \mathrm{E}+12$ \\
\hline Ho-166 & $1.45 \mathrm{E}+16$ & Tm-170 & $4.45 \mathrm{E}+13$ \\
\hline Ir-192 & $8.12 \mathrm{E}+14$ & Yb-169 & $3.10 \mathrm{E}+15$ \\
\hline Mn-54 & $2.66 \mathrm{E}+14$ & Zn-65 & $1.48 \mathrm{E}+14$ \\
\hline Pb-210 & $1.44 \mathrm{E}+12$ & Zr-95 & $8.96 \mathrm{E}+14$ \\
\hline Pd-103 & $2.19 \mathrm{E}+15$ & & \\
\hline
\end{tabular}




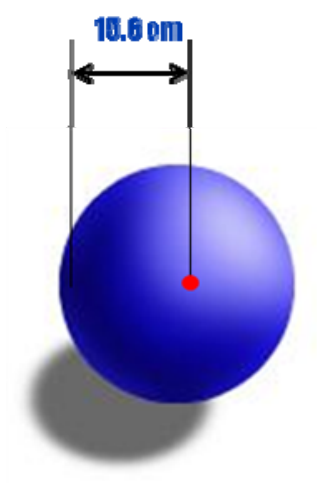

Figure 1. Representation of Voided Sphere Model

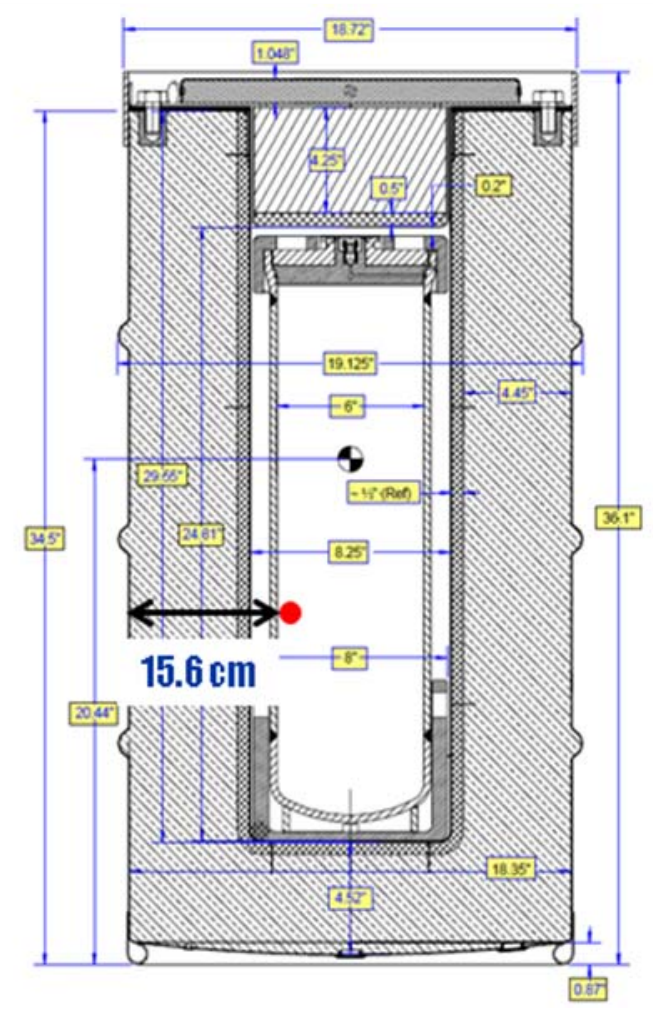

Figure 2. Diagram of Model 9977-96 Radioactive Material Transportation Package 


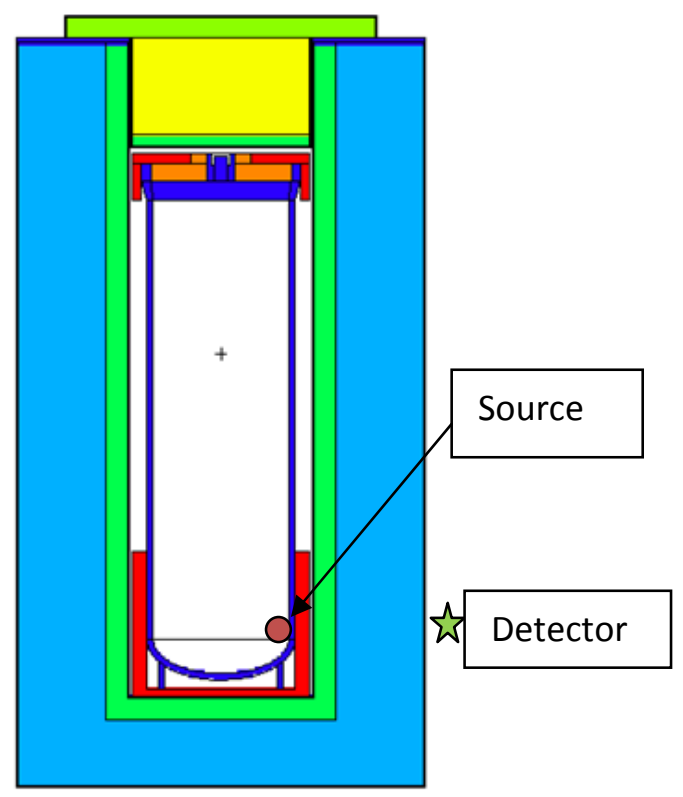

Figure 3. MCNP Input Model Used in the Shielding Calculations

Using the source terms in Tables 2 and 3 and the shielding models described, the mass of each isotope in Table 1 that results in a dose rate at the point of dose rate determination of $190 \mathrm{mrem} / \mathrm{hr}$ was calculated using the Monte Carlo radiation transport computer code MCNP for both the Voided Sphere Model and for the Model 9977-96. The sources were treated as point sources in the simulation, though it is shown as a sphere of finite volume in Figure 2 for the purposes of clarity. For the Model 9977-96, the limiting dose rate occurred on the external side surface of the package, which corresponds to the distance $15.6 \mathrm{~cm}$.

The approach used to derive the results presented in this report, in terms of developing the source terms, the shielding model, and the calculations, are consistent with the guidance provided in Regulatory Guide 7.9, Standard Format and Content of Part 71 Applications for Approval of Packages for Radioactive Material, ${ }^{[9]}$ and in the Packaging Review Guide for Reviewing Safety Analysis Reports for Packaging. ${ }^{[10]}$

\section{Results and Discussion}

The isotopic masses that result in a dose rate of $190 \mathrm{mrem} / \mathrm{hr}$ at a distance of $15.6 \mathrm{~cm}$ using the Voided Sphere Model are listed in Tables $4 \mathrm{a}$ and $4 \mathrm{~b}$. All sources are assumed to be point sources, thus conservatively neglecting any self-shielding. The isotopic masses listed in Tables $4 \mathrm{a}$ and $4 \mathrm{~b}$ were calculated assuming no shielding with only an air gap between the point source and the location of the assumed dose rate. 
Table 4a. Limiting Isotopic Masses for Neutron Sources Using Voided Sphere Model Isotopic Mass Limits for Voided Sphere Model [grams]: Distance=15.6 cm, Dose Rate=190 mrem/hr

\begin{tabular}{|c|c|c|c|c|c|c|c|c|c|c|}
\hline \multicolumn{11}{|c|}{ Isotopic Mass Limits for Voided Sphere Model [grams]: Distance $=15.6 \mathrm{~cm}$, Dose Rate $=190 \mathrm{mrem} / \mathrm{hr}$} \\
\hline & \multicolumn{10}{|c|}{$\begin{array}{l}\text { Weight Percent Beryllium } \\
\end{array}$} \\
\hline Isotope & $\mathbf{0}$ & 0.1 & 0.5 & 1 & 5 & 10 & 30 & 50 & 70 & 90 \\
\hline Am-241 & $2.99 \mathrm{E}-03$ & 2.99E-03 & $2.99 \mathrm{E}-03$ & $2.99 \mathrm{E}-03$ & $2.98 \mathrm{E}-03$ & $2.98 \mathrm{E}-03$ & $\begin{array}{c}2.97 \mathrm{E}-03 \\
\end{array}$ & $2.97 \mathrm{E}-03$ & $2.97 \mathrm{E}-03$ & $2.96 \mathrm{E}-03$ \\
\hline Am-243 & $2.78 \mathrm{E}-02$ & $\mathrm{NC}$ & $\mathrm{NC}$ & $\mathrm{NC}$ & $\mathrm{NC}$ & $2.78 \mathrm{E}-02$ & $2.78 \mathrm{E}-02$ & $2.77 \mathrm{E}-02$ & $2.77 \mathrm{E}-02$ & $2.77 \mathrm{E}-02$ \\
\hline Cf-252 & $1.92 \mathrm{E}-06$ & NA & NA & NA & NA & NA & NA & NA & NA & NA \\
\hline Cm-244 & $8.96 \mathrm{E}-04$ & $8.96 \mathrm{E}-04$ & $8.95 \mathrm{E}-04$ & 8.94E-04 & $8.90 \mathrm{E}-04$ & $8.84 \mathrm{E}-04$ & $8.68 \mathrm{E}-04$ & $8.57 \mathrm{E}-04$ & $8.50 \mathrm{E}-04$ & $8.44 \mathrm{E}-04$ \\
\hline Cm-248 & $1.12 \mathrm{E}-01$ & NA & NA & NA & NA & NA & NA & NA & NA & NA \\
\hline Np-237 & $6.06 \mathrm{E}+00$ & $\mathrm{NC}$ & $\mathrm{NC}$ & $\mathrm{NC}$ & $\mathrm{NC}$ & $6.05 \mathrm{E}+00$ & $6.05 \mathrm{E}+00$ & $6.05 \mathrm{E}+00$ & $6.05 \mathrm{E}+00$ & $6.05 \mathrm{E}+0 \mathrm{c}$ \\
\hline Pu-238 & $4.01 \mathrm{E}-03$ & $4.00 \mathrm{E}-03$ & $4.00 \mathrm{E}-03$ & $4.00 \mathrm{E}-03$ & $3.98 \mathrm{E}-03$ & $3.96 \mathrm{E}-03$ & $3.91 \mathrm{E}-03$ & $3.87 \mathrm{E}-03$ & $3.84 \mathrm{E}-03$ & $3.82 \mathrm{E}-03$ \\
\hline Pu-239 & $2.51 \mathrm{E}+00$ & $2.51 \mathrm{E}+00$ & $2.51 \mathrm{E}+00$ & $2.51 \mathrm{E}+00$ & $2.49 \mathrm{E}+00$ & $2.47 \mathrm{E}+00$ & $2.40 \mathrm{E}+00$ & $2.36 \mathrm{E}+00$ & $2.34 \mathrm{E}+00$ & $2.32 \mathrm{E}+0 \mathrm{C}$ \\
\hline Pu-240 & $3.17 \mathrm{E}-01$ & $3.17 \mathrm{E}-01$ & $3.17 \mathrm{E}-01$ & $3.17 \mathrm{E}-01$ & $3.16 \mathrm{E}-01$ & $3.15 \mathrm{E}-01$ & $3.11 \mathrm{E}-01$ & $3.08 \mathrm{E}-01$ & $3.07 \mathrm{E}-01$ & $3.05 \mathrm{E}-01$ \\
\hline Pu-241 & $3.35 \mathrm{E}-03$ & $\mathrm{NC}$ & $\mathrm{NC}$ & $\mathrm{NC}$ & $\mathrm{NC}$ & $3.35 \mathrm{E}-03$ & $3.34 \mathrm{E}-03$ & $3.34 \mathrm{E}-03$ & $3.33 \mathrm{E}-03$ & $3.33 \mathrm{E}-03$ \\
\hline Pu-242 & $2.18 \mathrm{E}+01$ & $2.18 \mathrm{E}+01$ & $2.18 \mathrm{E}+01$ & $2.18 \mathrm{E}+01$ & $2.17 \mathrm{E}+01$ & $2.16 \mathrm{E}+01$ & $2.13 \mathrm{E}+01$ & $2.12 \mathrm{E}+01$ & $2.11 \mathrm{E}+01$ & $2.10 \mathrm{E}+01$ \\
\hline
\end{tabular}

$\mathrm{NC}=$ Not Calculated

$\mathrm{NA}=$ Not Applicable

Table 4b. Limiting Isotopic Masses for Gamma Sources Using Voided Sphere Model

\begin{tabular}{|c|c|c|c|}
\hline \multicolumn{4}{|c|}{$\begin{array}{l}\text { Isotopic Mass Limts for Voided Sphere Model [grams]: } \\
\text { Distance }=15.6 \mathrm{~cm} \text {, Dose Rate }=190 \mathrm{mrem} / \mathrm{hr}\end{array}$} \\
\hline Is otope & Mass Limit [g] & Isotope & Mass Limit [g] \\
\hline Ac-227 & 6.92E-05 & Pm-147 & 5.74E-04 \\
\hline Cd-109 & $8.07 \mathrm{E}-06$ & Po-210 & $1.95 \mathrm{E}-01$ \\
\hline Co-60 & $2.95 \mathrm{E}-06$ & Ra-226 & $2.98 \mathrm{E}-03$ \\
\hline Cs-137 & $7.78 \mathrm{E}-05$ & Ru-106 & $2.86 \mathrm{E}-06$ \\
\hline Eu-152 & $3.49 \mathrm{E}-05$ & Sc-46 & $1.18 \mathrm{E}-07$ \\
\hline Fe-59 & $1.39 \mathrm{E}-07$ & Se-75 & $5.90 \mathrm{E}-07$ \\
\hline Gd-153 & $7.56 \mathrm{E}-06$ & Sm-145 & $1.24 \mathrm{E}-05$ \\
\hline Hf-181 & $6.51 \mathrm{E}-07$ & Sr-90 & $3.21 \mathrm{E}-04$ \\
\hline Нo-166 & 4.70E-08 & Tm-170 & $1.25 \mathrm{E}-05$ \\
\hline Ir-192 & $8.05 \mathrm{E}-07$ & Yb-169 & $4.85 \mathrm{E}-07$ \\
\hline Mn-54 & $1.19 \mathrm{E}-06$ & Zn-65 & $1.76 \mathrm{E}-06$ \\
\hline $\mathrm{Pb}-210$ & $2.80 \mathrm{E}-04$ & Zr-95 & $4.08 \mathrm{E}-07$ \\
\hline Pd-103 & $1.74 \mathrm{E}-07$ & & \\
\hline
\end{tabular}


The isotopic masses in the Model $9977-96$ radioactive material transportation container that result in an external dose rate on the surface of the package of $190 \mathrm{mrem} / \mathrm{hr}$ are given in Tables $5 \mathrm{a}$ and $5 \mathrm{~b}$.

Table 5a. Limiting Isotopic Masses for Neutron Sources Using Model 9977-96 Radioactive Material Transportation Package

\begin{tabular}{|c|c|c|c|c|c|c|c|c|c|c|}
\hline \multirow[b]{3}{*}{ Isotope } & \multicolumn{10}{|c|}{ Isotopic Mass Limits for Model 9977 Packaging [grams]: Distance $=15.6 \mathrm{~cm}$, Dose Rate $=190 \mathrm{mrem} / \mathrm{hr}$} \\
\hline & \multicolumn{10}{|c|}{\begin{tabular}{|l|l} 
Weight Percent Beryllium \\
\end{tabular}} \\
\hline & $\mathbf{0}$ & 0.1 & 0.5 & 1 & 5 & 10 & 30 & 50 & 70 & 90 \\
\hline Am-241 & $1.65 \mathrm{E}+01$ & $1.49 \mathrm{E}+01$ & $1.08 \mathrm{E}+01$ & $7.94 \mathrm{E}+00$ & $2.86 \mathrm{E}+00$ & $1.59 \mathrm{E}+00$ & $6.96 \mathrm{E}-01$ & 5.04E-01 & $4.20 \mathrm{E}-01$ & $3.74 \mathrm{E}-01$ \\
\hline Am-243 & $3.91 \mathrm{E}-01$ & $\mathrm{NC}$ & $\mathrm{NC}$ & $\mathrm{NC}$ & $\mathrm{NC}$ & $3.87 \mathrm{E}-01$ & $3.81 \mathrm{E}-01$ & $3.77 \mathrm{E}-01$ & $3.74 \mathrm{E}-01$ & $3.72 \mathrm{E}-01$ \\
\hline Cf-252 & $1.77 \mathrm{E}-06$ & NA & NA & NA & NA & NA & NA & NA & NA & NA \\
\hline Cm-244 & $3.84 \mathrm{E}-01$ & $3.53 \mathrm{E}-01$ & $2.76 \mathrm{E}-01$ & $2.29 \mathrm{E}-01$ & $9.14 \mathrm{E}-02$ & $5.28 \mathrm{E}-02$ & $2.36 \mathrm{E}-02$ & $1.72 \mathrm{E}-02$ & $1.45 \mathrm{E}-02$ & $1.28 \mathrm{E}-02$ \\
\hline Cm-248 & $1.04 \mathrm{E}-01$ & NA & NA & NA & NA & NA & NA & NA & NA & NA \\
\hline Np-237 & $7.97 \mathrm{E}+01$ & $\mathrm{NC}$ & $\mathrm{NC}$ & $\mathrm{NC}$ & $\mathrm{NC}$ & $7.92 \mathrm{E}+01$ & $7.86 \mathrm{E}+01$ & $7.82 \mathrm{E}+01$ & $7.79 \mathrm{E}+01$ & $7.77 \mathrm{E}+01$ \\
\hline Pu-238 & $4.18 \mathrm{E}+00$ & $3.69 \mathrm{E}+00$ & $2.51 \mathrm{E}+00$ & $1.77 \mathrm{E}+00$ & $5.97 \mathrm{E}-01$ & $3.22 \mathrm{E}-01$ & $1.41 \mathrm{E}-01$ & $1.02 \mathrm{E}-01$ & $8.46 \mathrm{E}-02$ & $7.51 \mathrm{E}-02$ \\
\hline Pu-239 & $1.16 \mathrm{E}+03$ & $1.04 \mathrm{E}+03$ & $7.62 \mathrm{E}+02$ & $5.55 \mathrm{E}+02$ & $2.02 \mathrm{E}+02$ & $1.11 \mathrm{E}+02$ & $4.91 \mathrm{E}+01$ & $3.56 \mathrm{E}+01$ & $2.97 \mathrm{E}+01$ & $2.65 \mathrm{E}+01$ \\
\hline Pu-240 & $2.67 \mathrm{E}+03$ & $1.40 \mathrm{E}+03$ & $4.84 \mathrm{E}+02$ & $2.67 \mathrm{E}+02$ & $6.39 \mathrm{E}+01$ & $3.33 \mathrm{E}+01$ & $1.39 \mathrm{E}+01$ & $1.00 \mathrm{E}+01$ & $8.14 \mathrm{E}+00$ & $7.29 \mathrm{E}+00$ \\
\hline Pu-241 & $2.03 \mathrm{E}+01$ & $\mathrm{NC}$ & $\mathrm{NC}$ & $\begin{array}{l}\mathrm{NC} \\
\end{array}$ & $\begin{array}{l}\mathrm{NC} \\
\end{array}$ & $1.79 \mathrm{E}+00$ & $7.83 \mathrm{E}-01$ & $5.67 \mathrm{E}-01$ & $4.73 \mathrm{E}-01$ & $4.20 \mathrm{E}-01$ \\
\hline Pu-242 & $2.22 \mathrm{E}+03$ & $2.15 \mathrm{E}+03$ & $2.10 \mathrm{E}+03$ & $1.95 \mathrm{E}+03$ & $1.51 \mathrm{E}+03$ & $1.14 \mathrm{E}+03$ & $6.70 \mathrm{E}+02$ & $5.33 \mathrm{E}+02$ & $4.64 \mathrm{E}+02$ & $4.18 \mathrm{E}+02$ \\
\hline
\end{tabular}

$\mathrm{NC}=$ Not Calculated

NA=Not Applicable

Table 5b. Limiting Isotopic Masses for Gamma Sources Using Model 9977-96 Radioactive Material Transportation Package

\begin{tabular}{|c|c|c|c|}
\hline \multicolumn{4}{|c|}{$\begin{array}{c}\text { Isotopic Mass Limts for Model } 9977 \text { Packaging [grams]: } \\
\text { Distance }=15.6 \mathrm{~cm} \text {, Dose Rate }=190 \mathrm{mrem} / \mathrm{hr}\end{array}$} \\
\hline Is otope & Mass Limit [g] & Isotope & Mass Limit [g] \\
\hline Ac-227 & $4.05 \mathrm{E}-04$ & Pm-147 & $3.31 \mathrm{E}-01$ \\
\hline Cd-109 & $3.73 \mathrm{E}-02$ & Po-210 & $2.54 \mathrm{E}-01$ \\
\hline Co-60 & $3.92 \mathrm{E}-06$ & Ra-226 & $6.15 \mathrm{E}-03$ \\
\hline Cs-137 & $1.97 \mathrm{E}-04$ & Ru-106 & $9.93 \mathrm{E}-06$ \\
\hline Eu-152 & $5.48 \mathrm{E}-05$ & Sc-46 & $1.57 \mathrm{E}-07$ \\
\hline Fe-59 & $1.79 \mathrm{E}-07$ & Se-75 & $2.21 \mathrm{E}-06$ \\
\hline Gd-153 & $2.32 \mathrm{E}-04$ & Sm-145 & $1.47 \mathrm{E}-02$ \\
\hline Hf-181 & $1.25 \mathrm{E}-06$ & Sr-90 & $4.15 \mathrm{E}-03$ \\
\hline Ho-166 & $4.30 \mathrm{E}-07$ & Tm-170 & $4.21 \mathrm{E}-04$ \\
\hline Ir-192 & $1.39 \mathrm{E}-06$ & Yb-169 & $3.51 \mathrm{E}-06$ \\
\hline Mn-54 & $1.56 \mathrm{E}-06$ & Zn-65 & $2.27 \mathrm{E}-06$ \\
\hline $\mathrm{Pb}-210$ & $1.93 \mathrm{E}-02$ & Zr-95 & $5.56 \mathrm{E}-07$ \\
\hline Pd-103 & $1.33 \mathrm{E}-03$ & & \\
\hline
\end{tabular}


The calculated limiting masses of the neutron-emitters using the Voided Sphere Model (see Table 4a) ranged from 21 grams for $\mathrm{Pu}-242$ to $1.92 \times 10^{-6}$ grams for $\mathrm{Cf}-252$. The limiting masses from largest to smallest were ordered as follows: $\mathrm{Pu}-242>\mathrm{Np}-237>\mathrm{Pu}-239>\mathrm{Pu}-240$ $>$ Cm-248 > Am-243 > Pu-238 > Pu-241 > Am-241 > Cm-244 > Cf-252.

The calculated limiting masses of gamma-emitters using the Voided Sphere Model (see Table $4 \mathrm{~b}$ ) ranged from 0.195 grams for Po-210 to $4.70 \times 10^{-8}$ grams for Ho- 166 . The limiting masses from largest to smallest were ordered as follows: Po-210 $>$ Ra-226 $>$ Pm-147 $>$ Sr-90 $>$ $\mathrm{Pb}-210>$ Cs-137 $>$ Ac-227 $>$ Eu-152 $>$ Tm-170 $>$ Sm-145 $>$ Cd-109 $>$ Gd-153 $>$ Co-60 $>$ Ru$106>$ Zn-65 $>$ Mn-54 $>$ Ir-192 $>$ Hf-181 $>$ Se-75 $>$ Yb-169 $>$ Zr-95 $>$ Pd-103 $>$ Fe-59 $>$ Sc-46 $>$ Ho-166.

As can be seen from examination of Table $4 \mathrm{a}$, the allowable limiting masses of the neutronemitters are rather insensitive to the beryllium concentration. This observation can be explained by the fact that the dose rates, and correspondingly the limiting masses, of the neutron-emitters are governed mainly by their gamma emissions when using the Voided Sphere Model. This is in contrast to the limiting masses for actinides with different beryllium concentrations when using the Model 9977-96 Package (see Table 5a), where a significant amount of the gamma rays are attenuated by the packaging (i.e., stainless steel containment vessel, foam, and stainless steel drum), and the dose rates (and limiting masses) are mainly governed by the neutron emissions.

The calculated limiting masses of the neutron-emitters using the Model 9977-96 Package (see Table 5a) ranged from $2.67 \times 10^{3}$ grams for $\mathrm{Pu}-240$ to $1.77 \times 10^{-6}$ grams for $\mathrm{Cf}-252$ for isotopes with no beryllium contamination. The limiting masses from largest to smallest were ordered as follows (no beryllium contamination): $\mathrm{Pu}-240>\mathrm{Pu}-242>\mathrm{Pu}-239>\mathrm{Np}-237>\mathrm{Pu}-241>\mathrm{Am}-241$ $>\mathrm{Pu}-238>\mathrm{Am}-243>\mathrm{Cm}-244>\mathrm{Cm}-248>\mathrm{Cf}-252$. Note that all of the neutron-emitting isotopes considered, except $\mathrm{Cf}-252$, had limiting masses greater than 0.1 grams when using the Model 9977-96 Package. It should also be recognized that the limiting masses for Pu-239, $\mathrm{Pu}-240$, and $\mathrm{Pu}-242$ cannot be considered "small gram quantities" since they are all more than one kilogram.

Since the limiting masses for some isotopes were quite large, there was a concern that the assumption that the sources were point sources may not result in the most limiting mass. Additional analyses for Pu-239 were performed whereby the sources were not assumed to be point sources but were assumed to be volume sources, consistent with their densities and the point source mass limits, and subcritical multiplication was taken into account. However, the self-shielding that occurs in the volume sources and the geometry effect of a volume source, more than compensated for the additional neutrons produced by subcritical multiplication, resulting in the the point source models producing the most conservative values (i.e., lowest) for the limiting masses. It should be noted that these results are for homogeneous mixtures of beryllium and actinides and thus yield conservative mass limits. For actinides and beryllium combined in a different physical form, the mass limits could be higher.

The calculated limiting masses of gamma-emitters using the Model 9977-96 Package (see Table 5b) ranged from 0.331 grams for Pm-147 to $1.57 \times 10^{-7}$ grams for Sc-46. The limiting masses from largest to smallest were ordered as follows: Pm-147 > Po-210 $>$ Cd-109 $>$ Pb-210 
$>$ Sm-145 $>$ Ra-226 $>$ Sr-90 $>$ Pd-103 $>$ Tm-170 $>$ Ac-227 $>$ Gd-153 $>$ Cs-137 $>$ Eu-152

$>$ Ru-106 $>$ Co-60 $>$ Yb-169 $>$ Zn-65 $>$ Se-75 $>$ Mn-54 $>$ Ir-192 $>$ Hf-181 $>$ Zr-95 $>$ Ho-166

$>$ Fe-59 $>$ Sc-46.

It is of interest to determine the difference between masses calculated using the Voided Sphere Model and those calculated when the package materials of the Model 9977-96 are taken into consideration. See Tables $6 a$ and $6 \mathrm{~b}$ for the fraction of allowable masses of the isotopes calculated with the Voided Sphere Model to the Model 9977-96 Package (i.e., in the Model 9977-97 Package without and with the package materials present).

Table 6a. Fraction of Allowable Mass in Voided Sphere Model to Allowable Mass in the Model 9977-96 Radioactive Material Transportation Package for Neutron Emitters

\begin{tabular}{|c|c|c|c|c|c|c|c|c|c|c|}
\hline \multicolumn{1}{|c|}{ Fraction of Allowable Mass in Voided Sphere Model to Allowable Mass in the Model 9977-96 Radioactive Mate rial } \\
Transportation Package \\
\hline \\
\hline $\mathbf{9}$
\end{tabular}

$\mathrm{NC}=$ Not Calculated

$\mathrm{NA}=$ Not Applicable

Table 6b. Fraction of Allowable Mass in Voided Sphere Model to Allowable Mass in the Model 9977-96 Radioactive Material Transportation Package for Gamma Emitters

\begin{tabular}{|c|c|c|c|}
\hline \multicolumn{2}{|l}{$\begin{array}{l}\text { Fraction of Allowable Mass in Voided Sphere Model to Allowable } \\
\text { Mass in the Model 9977-96 Radioactive Material Transportation }\end{array}$} \\
\hline & & & \\
Isotope & Fraction & Isotope & Fraction \\
\hline \hline Ac-227 & $1.71 \mathrm{E}-01$ & Pm-147 & $1.74 \mathrm{E}-03$ \\
\hline Cd-109 & $2.17 \mathrm{E}-04$ & Po-210 & $7.70 \mathrm{E}-01$ \\
\hline Co-60 & $7.54 \mathrm{E}-01$ & Ra-226 & $4.84 \mathrm{E}-01$ \\
\hline Cs-137 & $3.94 \mathrm{E}-01$ & Ru-106 & $2.88 \mathrm{E}-01$ \\
\hline Eu-152 & $6.37 \mathrm{E}-01$ & Sc-46 & $7.48 \mathrm{E}-01$ \\
\hline Fe-59 & $7.80 \mathrm{E}-01$ & Se-75 & $2.67 \mathrm{E}-01$ \\
\hline Gd-153 & $3.26 \mathrm{E}-02$ & Sm-145 & $8.40 \mathrm{E}-04$ \\
\hline Hf-181 & $5.23 \mathrm{E}-01$ & Sr-90 & $7.74 \mathrm{E}-02$ \\
\hline Ho-166 & $1.09 \mathrm{E}-01$ & Tm-170 & $2.98 \mathrm{E}-02$ \\
\hline Ir-192 & $5.81 \mathrm{E}-01$ & Yb-169 & $1.38 \mathrm{E}-01$ \\
\hline Mn-54 & $7.65 \mathrm{E}-01$ & Zn-65 & $7.74 \mathrm{E}-01$ \\
\hline Pb-210 & $1.45 \mathrm{E}-02$ & Zr-95 & $7.33 \mathrm{E}-01$ \\
\hline Pd-103 & $1.31 \mathrm{E}-04$ & \multicolumn{3}{|l}{} \\
\cline { 1 - 3 } & \multicolumn{3}{|l}{} \\
\cline { 1 - 3 } & &
\end{tabular}


An examination of the fraction of allowable mass from the Voided Sphere Model to allowable mass in the Model 9977-96 radioactive material transportation package for neutron emitters [excluding Cm-248 \& Cf-252] (Table 6a) shows that the fractions ranged from $1.19 \times 10^{-4}$ to $8.75 \times 10^{-2}$. These data show that the results from the Voided Sphere Model, for most neutron emitting isotopes, are conservative relative to the limiting masses for the Model 9977-96 Package. For the notable exceptions, which are Cm-248 and Cf-252, the results from the Voided Sphere Model are non conservative, by $7 \%$ and $8 \%$ respectively, relative to the limiting masses for these isotopes in the Model 9977-96. These seemingly non-intuitive results are due to the fact that the dose rates of these isotopes are dominated by neutrons, the very limited neutron shielding provided by the Model 9977-96 Package, and most importantly the scattering of neutrons by materials in the Model 9977-96 Package towards the point of dose rate detection (which, of course, does not occur in the Voided Sphere Model).

Since the mass limit results for $\mathrm{Cm}-248$ and Cf-252 obtained using the Voided Sphere Model are non-conservative relative to the mass limit results for these isotopes in the Model 9977-96 Package, it is suggested that for application of the Voided Sphere Model mass limits for Cm-248 and Cf-252 to transportation packages that the mass limits be reduced by about $10 \%$. This would ensure that the $5 \%$ conservative margin for the results obtained by assuming a dose rate of $190 \mathrm{mrem} / \mathrm{hr}$ is retained (recall that the regulatory dose rate limit on the external surface of the transportation package is $200 \mathrm{mrem} / \mathrm{hr}$ ).

When the fractions of allowable masses from the Voided Sphere Model to allowable masses in the Model 9977-96 Package for gamma emitters are examined (Table 6b), it is seen that the fractions are generally much higher than those of the neutron emitters and range from $1.31 \times 10^{-4}$ to 0.78 , with $68 \%$ of the gamma emitting isotopes considered having a fraction greater than 0.1 . For the gamma emitting isotopes, the relative conservatism of the results from the Voided Sphere Model to the Model 9977-96 Package is generally due to the fact that many have fairly soft gamma energy spectra. Lower energy gamma rays are appreciably attenuated by the packaging materials in the Model 9977-96, and therefore the results from the Voided Sphere Model for those cases are more conservative. In general, the gamma-emitting isotopes that have harder spectra will be identified by higher fractions in Table $6 \mathrm{~b}$.

It should be noted that the limiting isotopic masses presented in this document for the Model 9977-96 Package are based solely on external radiation level considerations, and that the actual limiting mass for transportation in this packaging under the restrictions of 10 CFR 71 and the Model 9977-96 Safety Analysis Report for Packaging (SARP) may be based on other considerations, such as criticality, mass, volume, and heat generation. The Model 9977-96 mass limits for both gamma emitters and neutron emitters are also applicable to Models 9978 and 9975 packagings noting that these mass limits will be on the conservative side for these two packagings.

\section{Applicability}

The isotopic limiting mass results from the Voided Sphere Model are widely applicable for general shielding considerations and to radioactive material packaging in particular. The Voided Sphere Model results can be conservatively applied (except the results for Cm-248 and Cf-252) to essentially any transportation or storage package since the model assumes no shielding is present. 
Additionally, the Voided Sphere Model results can be applied to shielding considerations as related to facility operations. The Voided Sphere Model data presented in this paper can be used as a reference for dose rates for unshielded sources, where the assumption of a point source is valid.

For application of the Voided Sphere Model results to a distance other than $15.6 \mathrm{~cm}$ or to a dose rate criterion of other than $190 \mathrm{mrem} / \mathrm{hr}$, the limiting mass would need to be scaled:

$$
M_{L P}=\left(\frac{D_{C}}{190}\right)\left(\frac{d_{p}}{15.6}\right)^{2} M_{L, 15.6}
$$

where:

$\mathrm{M}_{\mathrm{LP}} \quad$ is the isotopic mass limit [grams],

$\mathrm{d}_{\mathrm{P}} \quad$ is the distance for the package under consideration (usually the minimum distance from the inner wall of the containment vessel [cm],

$\mathrm{M}_{\mathrm{L}, 15.6}$ is the isotopic mass limit calculated using the Voided Sphere Model at a distance of $15.6 \mathrm{~cm}$ [grams] that produces a dose rate of $190 \mathrm{mrem} / \mathrm{hr}$, and

$\mathrm{D}_{\mathrm{C}} \quad$ is the dose rate criterion of interest [mrem $\left./ \mathrm{hr}\right]$.

For mixtures of isotopes, the sum of the fraction of each isotope to its individual limit should be less than or equal to 1 , i.e.,

$$
\sum_{i=1}^{n} \frac{M_{i}}{M_{L P}} \leq 1
$$

where:

$\mathrm{M}_{\mathrm{i}} \quad$ is the mass of the $\mathrm{i}^{\text {th }}$ isotope in the mixture containing $\mathrm{n}$ isotopes, and

$\mathrm{M}_{\mathrm{LP}} \quad$ is the maximum allowed mass for that isotope that may be calculated using Equation E1.

Equation E2 is applicable to both the Voided Sphere Model and the Model 9977-96 cases, where $\mathrm{M}_{\mathrm{LP}}$ is obtained from Tables $5 \mathrm{a}$ and $5 \mathrm{~b}$. Note that Equation E1 is not applicable to the Model 9977-96.

\section{Conclusions and Future Work}

This report presents a set of mass limits for commonly used sources and other material found at various DOE sites that can be shipped in unshielded containers or the Model 9977-96, Model 9978, and Model 9975 Packagings. For the case of common actinides that contain mixed in light elements, a conservative set of limits has been presented based on various levels of beryllium impurity.

This work could be extended in many aspects, including: (1) consideration of additional isotopes, such as additional medical and industrial isotopes, (2) additional transportation package-specific calculations, such as calculations of limiting isotopic masses for materials in the shielded inserts for the Model 9977-96, and (3) generic shielding calculations, where a given thickness of 
shielding, such as lead or polyethylene, is considered when determining the allowable mass limits. In addition, other medical, industrial, or rarely-shipped isotopes could be considered in future work.

The Model 9977-96 Package can be used with three different shielded containers or inserts: (1) the SGQ-SC1, which is made of lead and encapsulated in stainless steel with a threaded stainless steel closure, (2) the SGQ-SC2, which is constructed of high-density polyethylene (HDPE), and (3) the SGQ-SC3, which is constructed of tungsten and is also encapsulated in stainless steel. Additional calculations of isotopic mass limits in the Model 9977-96 could include considerations of the lead and tungsten shielded inserts for isotopes that are primarily gamma emitters, and consideration of the HDPE shielded insert for actinides with or without light element impurities that are primarily neutron emitters.

Finally, other future work could include developing a generalized approach for light element impurities other than beryllium. Although, use of the beryllium impurity concentrations for determining isotopic mass limits for other light element impurities is conservative, the mass limit envelope for alpha-emitting isotopes with these other light element impurities could be broadened and therefore optimize shipments. Since the alpha-neutron (i.e., $\alpha, n)$ behavior of light elements relative to beryllium is known, a generalized approach for determining the $(\alpha, n)$ behavior of alpha-emitting isotopes with light element impurities, including mixtures of isotopes with mixtures of light element impurities, could be developed. 


\section{References}

[1] P.S. Blanton, T. Wickland, \& H. Klebba, Development and Testing of the Blanton Clamshell Closure for use on Radioactive Material Packaging Drums, WSRC-STI-2007-00591, Proceeding of the $15^{\text {th }}$ International Symposium on the Packaging and Transportation of Radioactive Materials (PATRAM), Miami, Florida, October 21-26, 2007.

[2] R.W. Watkins, B.M. Loftin \& D.S. Hoang, Authorizing the DOT Specification 6M Packaging for Continued Use at the Savannah River Site, Savannah River National Laboratory, SRNL-STI-2010-00149.

[3] Title 10 of the Code of Federal Regulations, Part 71, Packaging and Transportation of Radioactive Material, Government Printing Office, February 12, 2009.

[4] Nathan, S. J., Ed., Radiation Source Term Analysis Code RASTA User Guide (U), WSMS-CRT-97-0013, Revision 4, Washington Safety Management Solutions, Aiken, SC, February 2004.

[5] ORIGEN-ARP, Versions 5.0/5.1.01, Isotope Generation and Depletion Code, CCC 725/732, Radiation Safety Information Computational Center, May 2004/March 2007.

[6] X5-Monte Carlo Team, MCNP-A General Monte Carlo N-Particle Transport Code, Version 5.1.40, Los Alamos National Laboratory, February 2006.

[7] USA/9977/B(M)F-96 (DOE), United States Department of Energy Certificate of Compliance for Radioactive Materials Packages, Model 9977, Revision 4, United States Department of Energy, Washington, DC, expires October 31, 2012.

[8] USA/9977/B(M)F-96 (DOE-S/T-1), United States Department of Energy Certificate of Compliance for Radioactive Materials Packages, Model 9977, Revision 0, United States Department of Energy, Washington, DC, expires December 31, 2013.

[9] Regulatory Guide, Office of Nuclear Regulatory Research, Regulatory Guide 7.9, Standard Format and Content of Part 71 Applications for Approval of Packages for Radioactive Material, Nuclear Regulatory Commission, Revision 2, March 2005.

[10] DiSabatino, et.al., Packaging Review Guide for Reviewing Safety Analysis Reports for Packaging, Lawrence Livermore National Laboratory, UCID-21218, Rev. 3, February 2008. 